\title{
Microtomographic Analysis of Impact Damage in FRP Composite Laminates: A Comparative Study
}

\author{
M. Alemi-Ardakani, ${ }^{1}$ A. S. Milani, ${ }^{1}$ S. Yannacopoulos, ${ }^{1}$ L. Bichler, ${ }^{1}$ D. Trudel-Boucher, ${ }^{2}$ \\ G. Shokouhi, ${ }^{3}$ and H. Borazghi ${ }^{3}$ \\ ${ }^{1}$ School of Engineering, University of British Columbia, Kelowna, Canada V1V 1V7 \\ ${ }^{2}$ Industrial Materials Institute, National Research Council, Boucherville, Canada J4B 6 Y4 \\ ${ }^{3}$ AS Composite Inc., Pointe-Claire, Canada H9R 4L6 \\ Correspondence should be addressed to A. S. Milani; abbas.milani@ubc.ca
}

Received 12 January 2013; Revised 15 April 2013; Accepted 21 April 2013

Academic Editor: Philip Harrison

Copyright (C) 2013 M. Alemi-Ardakani et al. This is an open access article distributed under the Creative Commons Attribution License, which permits unrestricted use, distribution, and reproduction in any medium, provided the original work is properly cited.

\begin{abstract}
With the advancement of testing tools, the ability to characterize mechanical properties of fiber reinforced polymer (FRP) composites under extreme loading scenarios has allowed designers to use these materials in high-level applications more confidently. Conventionally, impact characterization of composite materials is studied via nondestructive techniques such as ultrasonic C-scanning, infrared thermography, X-ray, and acoustography. None of these techniques, however, enable 3D microscale visualization of the damage at different layers of composite laminates. In this paper, a 3D microtomographic technique has been employed to visualize and compare impact damage modes in a set of thermoplastic laminates. The test samples were made of commingled polypropylene (PP) and glass fibers with two different architectures, including the plain woven and unidirectional. Impact testing using a drop-weight tower, followed by postimpact four-point flexural testing and nondestructive tomographic analysis demonstrated a close relationship between the type of fibre architecture and the induced impact damage mechanisms and their extensions.
\end{abstract}

\section{Introduction}

During experimental analysis of impact behaviour of FRP composites, it is common to use nondestructive/destructive detection methods to investigate the induced damage modes and their extension in test samples. Different nondestructive methods have been used in the literature, from simple visual methods [1-5] to more complex thermal- or electrical-based [6-9] methods, ultrasonic C-scanning [10-13], and X-ray imaging [14-16]. Each method has its own advantages and disadvantages and may be suitable for a particular application/material type. Nevertheless, a common limitation of these methods is that they are generally unable to give a full 3D image of the interior part of the material, hence making it difficult to provide complete information regarding the location and extent of different damage modes such as matrix cracking, fiber breakage, fiber pull-out, fiber-matrix debonding, and delamination. On the other extreme, the destructive methods have been of less desire for sensitive applications as they can be the source of additional damage in the impacted zone of structures such as fiber breakage, fiber pull-out, or delamination growth. The previous shortcomings can be well addressed by using today's advanced X-ray microtomography techniques (XMTs), which is the main focus of this paper. Namely, the present work aims at a detailed comparison of damage state in impacted woven fabric and unidirectional thermoplastic laminates via XMT, thereby arriving at a correlation between the observed damage distributions and the underlying reinforcement type.

1.1. Historical Background. X-ray microtomography technique (XMT) is known as a nondestructive technique for 3D microstructure reconstruction and visualization of the interior parts of objects with a resolution in the order of micrometers. Johann Radon, a Czech mathematician, was 


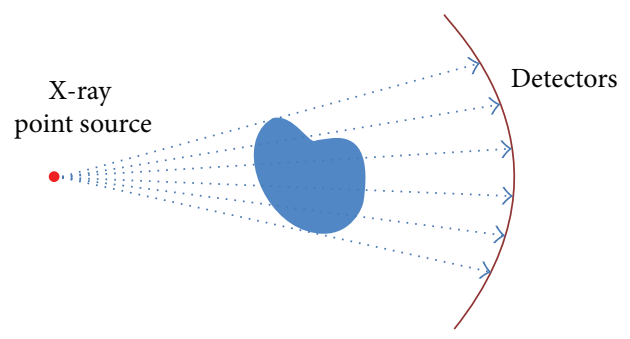

(a)

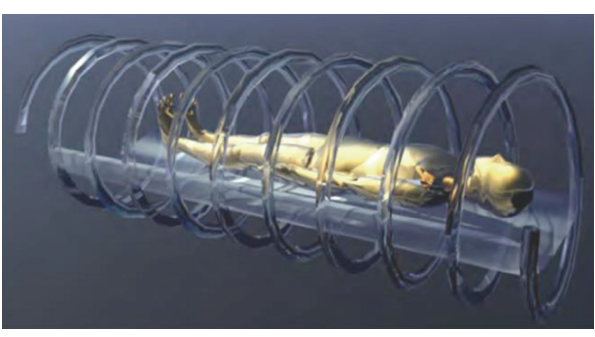

(b)

FIGURE 1: (a) Schematic of macrotomography used in medical examinations; (b) helical body scanning [17].

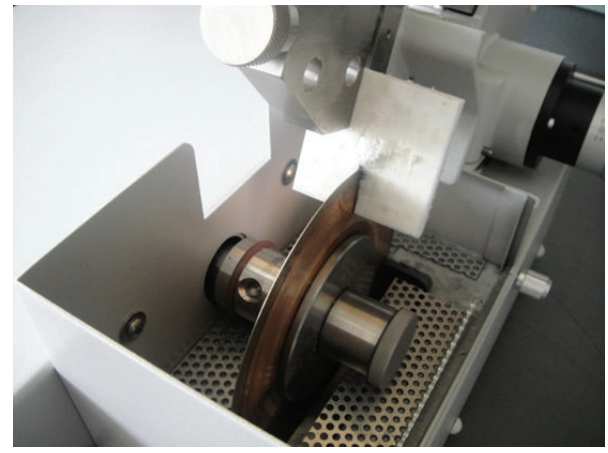

FIGURE 2: A high precision saw cutting the composite sample in the mid plane where the damage zone is present.

the first scientist who conceived a mathematical solution for the reconstruction of X-ray images in 1917 [17]. Allan Cormack, a South African physicist, continued the previous work and developed an algorithm for the geometrical reconstruction problem at Tufts University in 1964. Following this, Godfrey Hounsfield built the first CT (computed tomography) scanner at EMI Research Labs in the UK in 1972. It is worth mentioning that Cormack and Hounsfield received Nobel Prize in 1979 because of their contributions in building the first CT scanner and its effect on medical imaging applications [17]. Figure 1 shows a schematic of the macrotomography technique that today is used in medical examinations. Medical CT scanners use a point source Xray and an array of detectors. The patient body is inserted into the machine chamber. At the same time X-ray source and detectors rotate around the body and collect the X-ray images, that is, helical body scanning.

Because of the sensitivity of human body to high radiation exposure, the energy and dosage of $\mathrm{X}$-rays in these machines are set to be low and as a result the ensuing image resolutions are often low [18]. This limitation led Elliot and Dover in 1982 to build a more precise machine with higher exposure capability and image resolution $(12 \mu \mathrm{m})$ for industrial applications and microanalyses [19]. Another difference between the industrial microtomography machines (XMT) and the medical CT scanners is that the X-ray source and detectors in XMT machines are stationary and the sample rotates. Depending on the need, one can set the machine to take several thousands of scans in a complete rotation of the
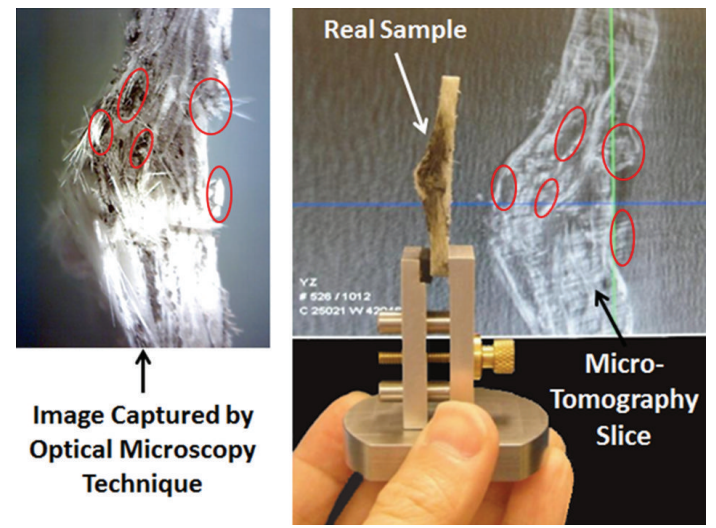

FIgURE 3: Comparison between the real impacted sample and the images obtained from nondestructive microtomography and destructive optical microscopy; red circles are to show comparable damage zones captured by the two methods.

sample between $0^{\circ}$ and $360^{\circ}$. Subsequently, postprocessing software is used to reconstruct the $3 \mathrm{D}$ image of the sample which contains all geometrical information of the interior microstructure.

1.2. Example of XMT for Composites. Before presenting the conducted case study, let us illustrate a general example of an XMT image (obtained by Xradia microXCT-400 machine) as compared to an image obtained from the same sample through a destructive method. Namely, an impacted composite sample was cut with a slow speed diamond saw (Figure 2) and the cross-section of the impacted zone was examined by an optical microscope (Figure 3). In the nondestructive counterpart of this analysis, the specimen needed no physical cutting and the XMT image (Figure 3) shows a slice (virtual cut) of the 3D image of the material microstructure in the midplane. The comparison of the two images shows that microtomography has captured the interior damages reasonably well. Slight differences between these images can be due to the damage induced during the cutting process in the destructive method (microscopy) such as fiber breakage, fiber pull-out, cracking, compressing or opening the delaminated layers, which in turn implies an advantage of using tomography as a nondestructive method. Additionally, in the destructive method the cut sample may not be used for 


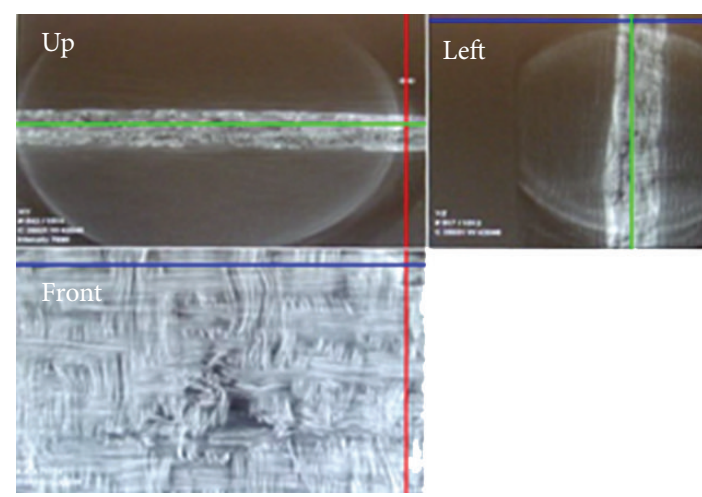

(a)

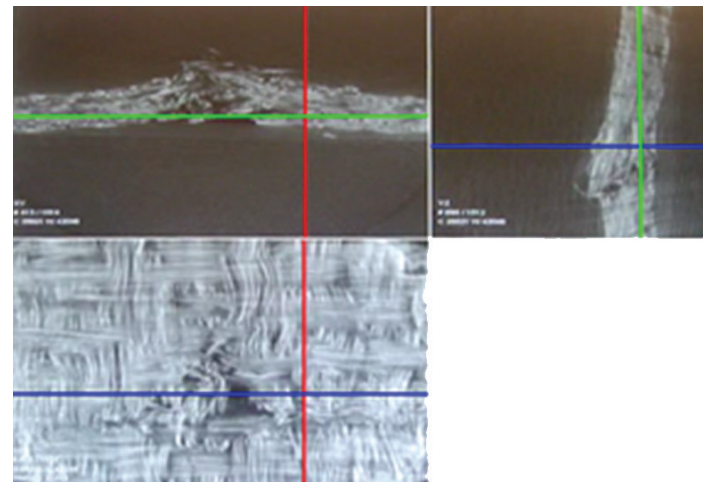

(c)

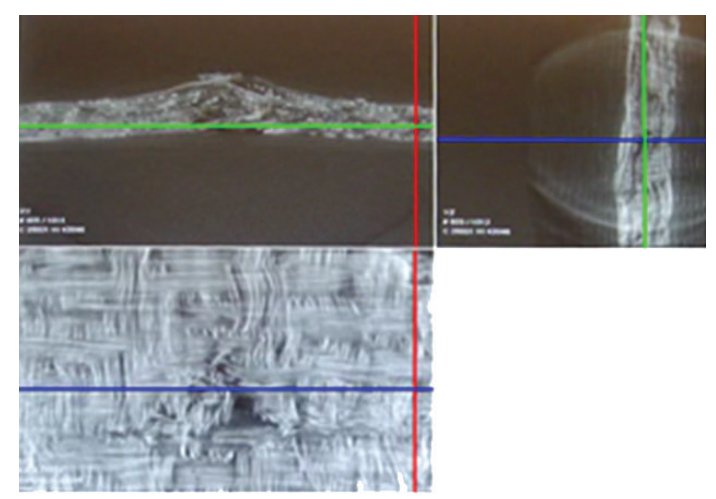

(b)

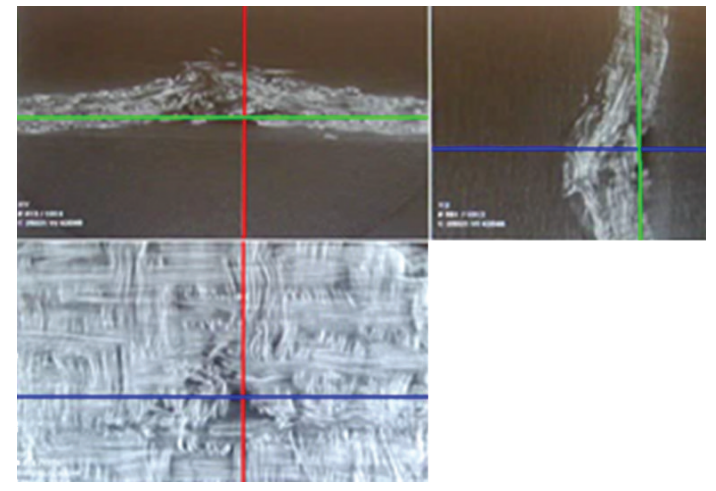

(d)

FIGURE 4: Example of the histogram of XMT analysis in an impacted laminate; the varying severity of fiber distortion, matrix cracking, and delamination can be noticed depending on the distance from the impact center.

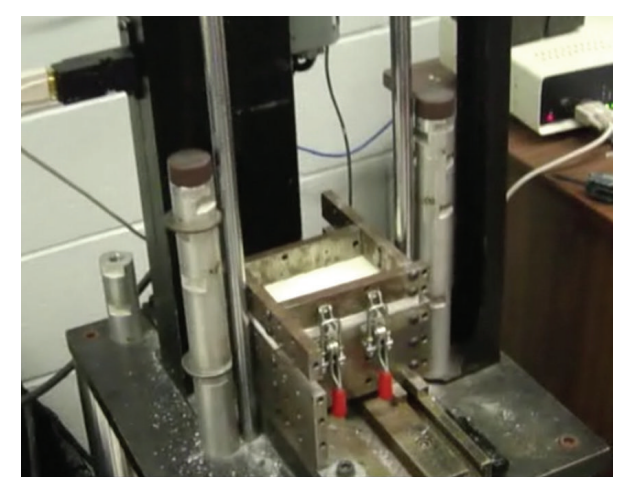

(a)

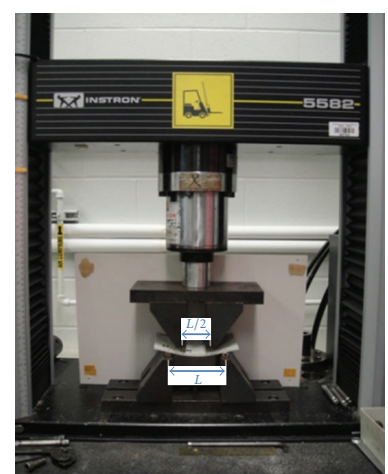

(b)

FIGURE 5: Set-up used during (a) the drop-weight impact testing and (b) postimpact four-point bending.

further investigations at different planes, whereas in the XMT the virtual cutting plane can be moved over the sample to scrutinize the microstructure in arbitrary sections. Figures $4(\mathrm{a})$ to $4(\mathrm{~d})$ show the trend (histogram) of such interactive analysis for four different cutting planes (namely, at different distances from the specimen center). Each XMT slice has four subimages (top, front, and left views). The cutting planes are shown by red, blue, and green lines. Figure 4(a) reveals the damaged cross-sections when the top and left cutting planes (blue and red lines) are far from the impact center as noted in the front view. Figure 4(b) shows the tomography slice when the top cutting plane (blue line) was placed near the impact center. In Figure 4(c), the left cutting plane (red line) was moved towards the impact center and in Figure 4(d) the left cutting plane was almost at the center where most of the damage is noticed from the side view.

\section{Case Study}

2.1. Sample Preparation. Two sets of test samples were prepared using vacuum bagging to laminate 12 layers of polypropylene/E-glass preform (with a fiber volume fraction 


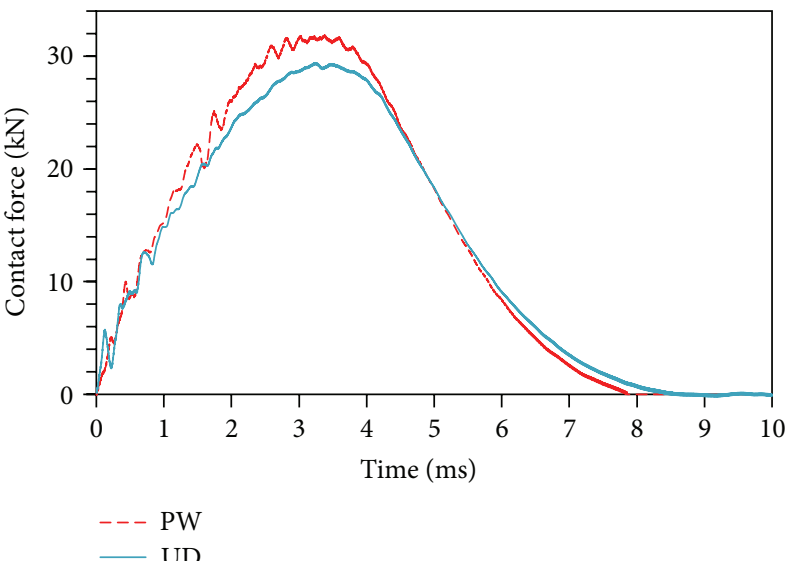

(a)

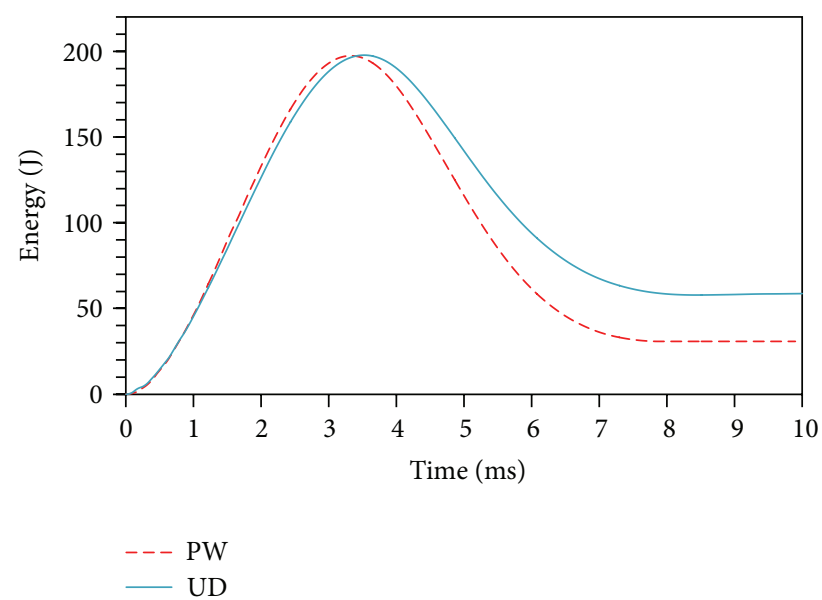

(c)

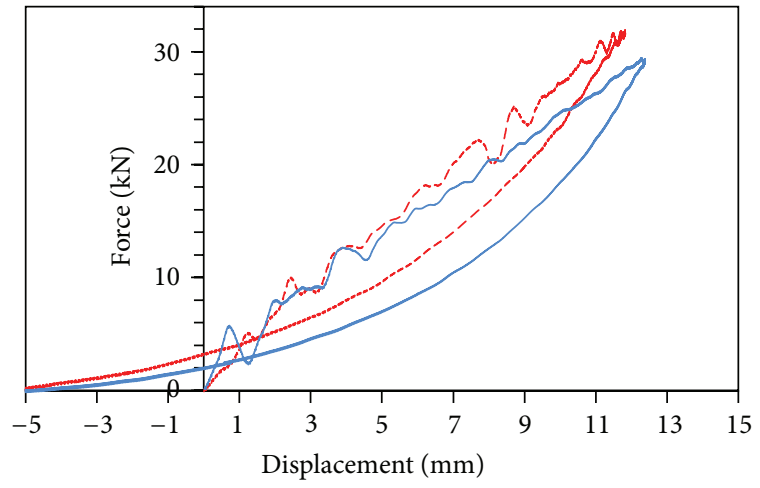

--- PW

(b)

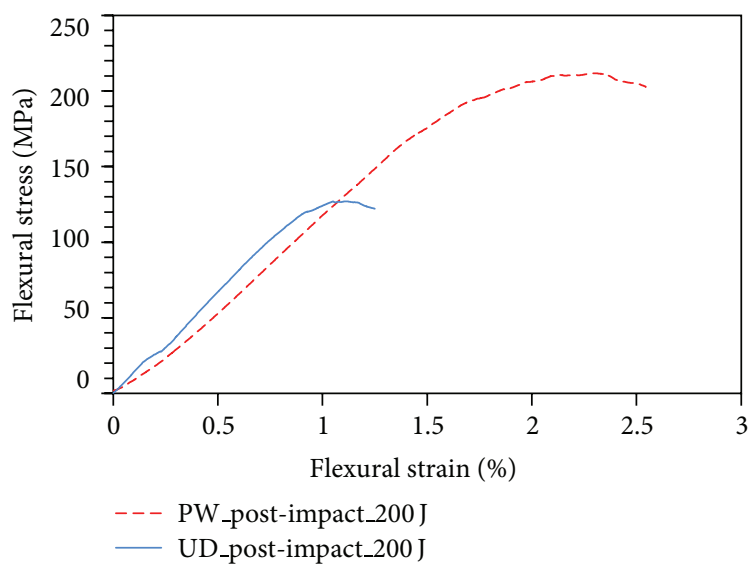

(d)

FIgURE 6: The average response curves of PW and UD samples subjected to $200 \mathrm{~J}$ impact loading; (a) impactor force versus time, (b) force versus displacement, (c) energy versus time, and (d) the postimpact flexural test results.

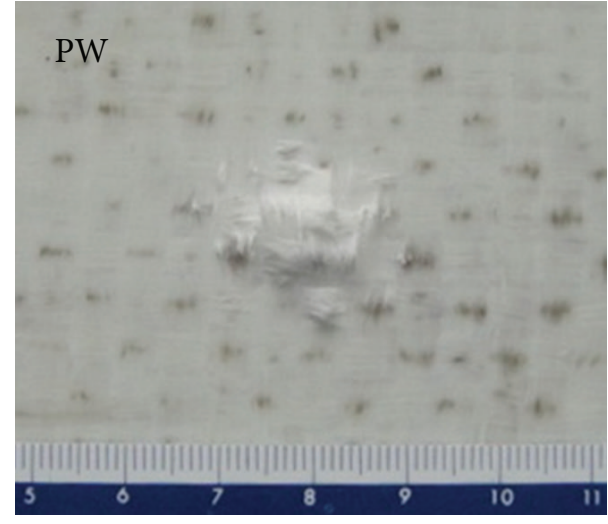

(a)

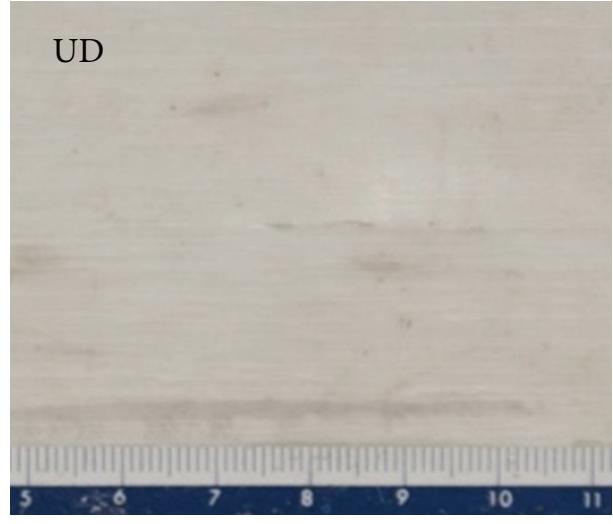

(b)

FIGURE 7: Rear face of the PW and UD samples subjected to $200 \mathrm{~J}$ impact energy. 


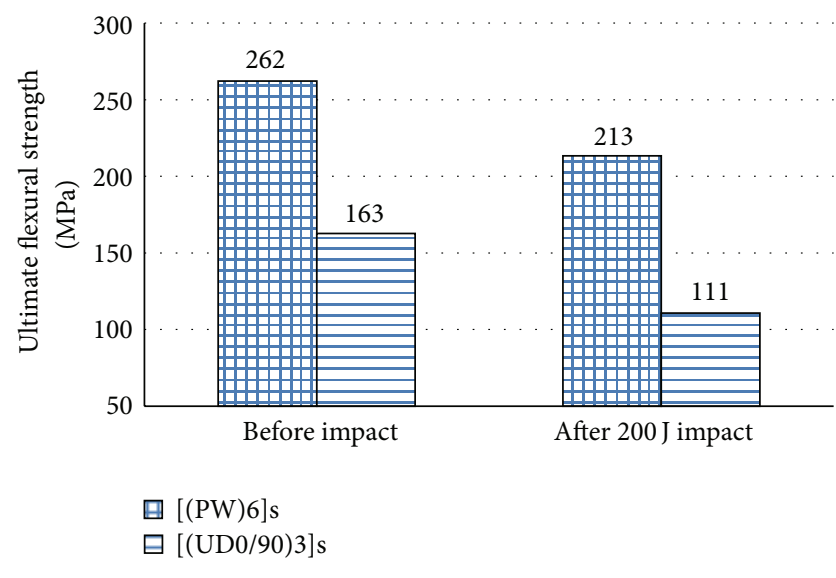

FIGURE 8: Ultimate flexural strength comparisons before and after impact tests on UD and PW laminates.

of $60 \%-70 \%)$ using two different reinforcement patterns including the plain woven (PW) and unidirectional (UD). The laminates' size was chosen for impact testing based on ASTM D7136 [20] with a rectangular shape $(150 \times 100 \mathrm{~mm})$ and the total thickness of $6 \mathrm{~mm}$.

2.2. Impact and Postimpact Flexural Testing. Each composite laminate type (PW or UD) was tested under a drop-weight tower (Figure 5(a)). Impact tests were conducted using Dynatup Model 8200 impact machine with a hemisphere projectile of 1 inch in diameter and $12.26 \mathrm{~kg}$ mass. Each test was repeated twice and all four sides of the specimens were completely clamped during the impact event. The impact energy was kept constant at $200 \mathrm{~J}$. Force history during the impact event was collected by a load cell, a quartz piezoelectric force sensor, mounted on the impactor. The acceleration of impactor as a function of time, $a(t)$, was calculated by Newton's second law of motion (1) from the collected force history $F(t)$ and the impactor mass $m$ :

$$
a(t)=\frac{F(t)}{m} .
$$

The velocity $v(t)$ and displacement of impactor $x(t)$ were found by numerical integration as

$$
\begin{gathered}
v(t)=v_{0}+g t-\int_{0}^{t} \frac{F(t)}{m} d t \\
x(t)=\int_{0}^{t} v(t) d t
\end{gathered}
$$

where $v_{0}$ is the velocity of impactor at the time of hitting the sample measured by an infrared velocity detector; see [21] for more details of drop-weight test kinematics. After impact testing, a postimpact four-point flexural experiment (Figure 5(b)) was conducted on each specimen. The motivation was to study the postimpact resistance of the impacted composite laminates for their potential application, for example, as a highway guardrail between inspection/repair intervals and also to find the deterioration of their effective mechanical properties due to the impact event. All the results presented in the next sections are normalised with respect to the fiber volume fraction.

2.3. Results of the Impact and Postimpact Bending Tests. Figures 6(a) and 6(b) show the average contact force and displacement of projectile from repeats of the test. In comparison to UD samples, Figure 6(a) suggests that PW has exerted more force to the impactor. The energy has been calculated via

$$
E(t)=\int_{0}^{x(t)} F(t) d x
$$

where $F$ is the reaction (contact) force and $x$ is the impactor displacement. Figure 6(c) shows the average energy of impactor for the two experiments. Subtraction of the energy of impactor at the time of hitting the sample $(200 \mathrm{~J})$ from that at the rebounce indicates the dissipated energy due to permanent damage in the material. This energy is represented by the area trapped between the penetration and rebound curves in Figure 6(b) or the final flat energy level in Figure 6(c) after about $8 \mathrm{~ms}$. According to these diagrams, UD laminates have absorbed more energy than PW laminates. Hence, it may be concluded that the absorbed energy has been decreased by increasing the reinforcement waviness from unidirectional to plain weave pattern, given comparable laminate thicknesses and fiber contents.

Figure 6(d) shows the average results of flexural testing for impacted samples. It confirms that the impacted plain woven composite has withstood postimpact bending forces much better than the impacted unidirectional composites. For comparison purposes, the four-point flexural testing was also performed on PW and UD healthy samples (i.e., before impact damage). Accordingly, Figure 8 indicated that the deterioration percent of ultimate flexural strength due to impact is $19 \%$ for the PW material and $32 \%$ for the UD material. This result is in agreement with the energy results in Figure 6(c): the more the absorbed energy by the material, the higher the deterioration of effective mechanical properties of the sample after the impact. Hence, we can conclude that UD samples have been damaged more severely than PW samples under impact. However a question would then be why is the visible (exterior) damage in PW samples much more apparent than UD samples as illustrated in Figure 7? XMT technique was employed to answer this question as it can illustrate the interior damage of the samples.

2.4. XMT Results. As addressed earlier, X-ray microtomography tests were conducted using Xradia microXCT-400 machine with sample dimensions of $6 \times 40 \times 120 \mathrm{~mm}$. Table 1 shows the acquisition parameters and the test set-up used during tomography. Images obtained by this technique comprised $1024 \times 1024$ pixels of $33.57 \mu \mathrm{m}$.

Figures 9(a) and 10(a) show the XMT images of PW and UD laminates at selected cross-sections. Figures 9 (b) and 10(b) show a $25 \mathrm{~mm} \times 10 \mathrm{~mm}$ window cropped from the top and left cross-section views of PW and UD specimens. Fiber layers are also marked in these images. Figures 9(c) and 10(c) 


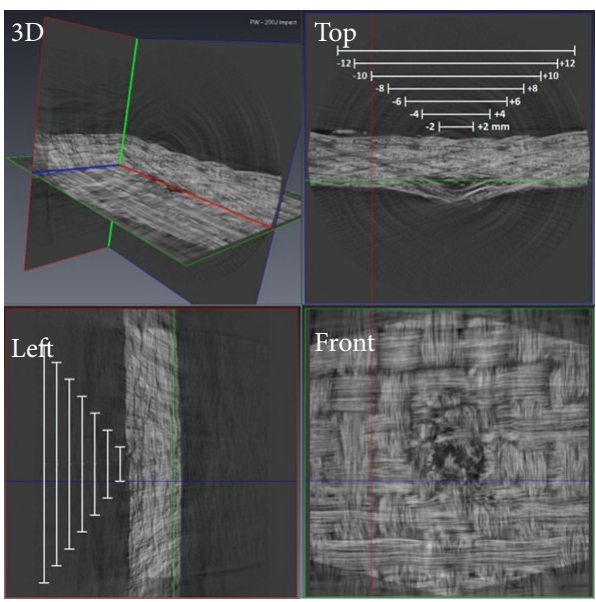

(a)

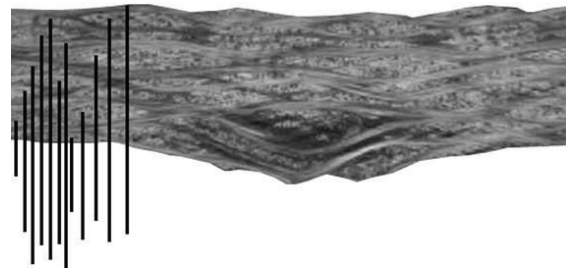

(b)

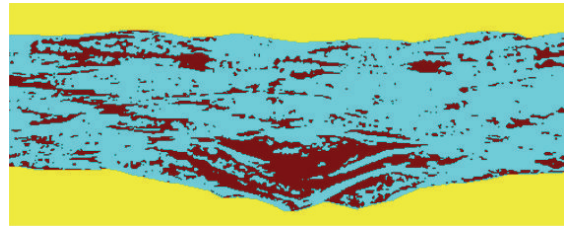

(c)

FIGURE 9: (a) XMT image of the impacted PW laminate (top view at the impact center, left view at $10 \mathrm{~mm}$ from the impact center, and front view close to the rear side of impact), (b) enlarged top view within a cropped window of $25 \mathrm{~mm} \times 10 \mathrm{~mm}$, and (c) the processed image of top view at the impact center (for subsequent damage quantification purposes).

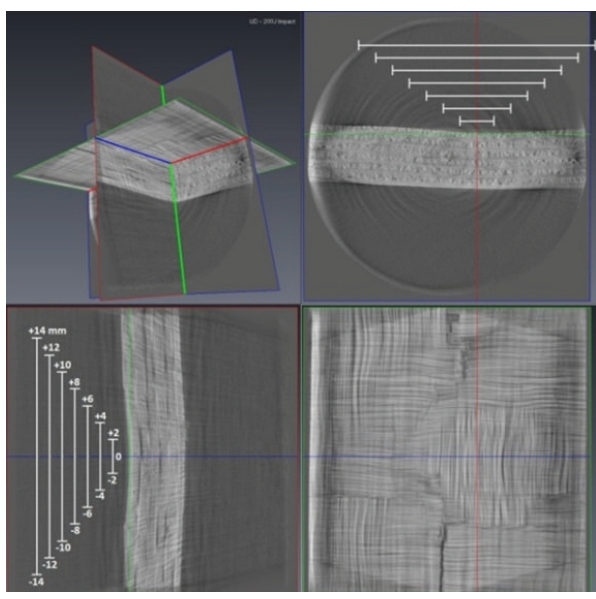

(a)

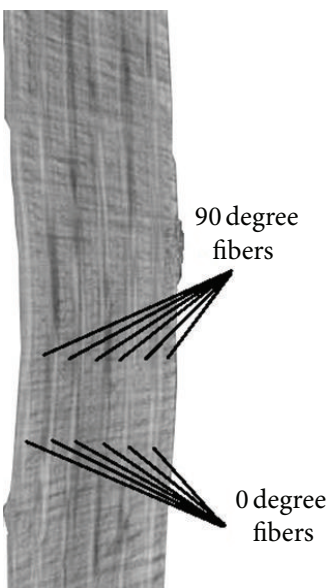

(b)

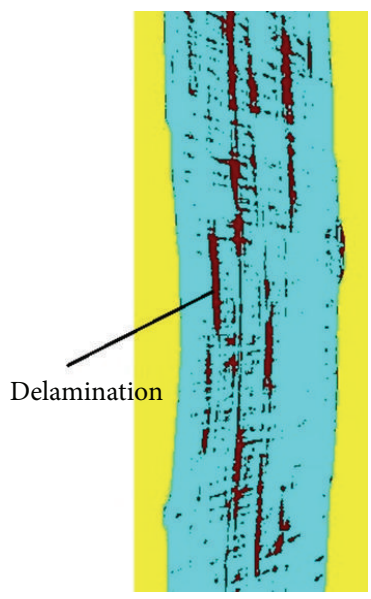

(c)

FIGURE 10: (a) XMT image of impacted UD laminate (top view at the impact center, left view at $10 \mathrm{~mm}$ to the impact center, and front view close to the rear side of impact), (b) enlarged left view within a cropped window of $25 \mathrm{~mm} \times 10 \mathrm{~mm}$, and (c) the processed image of left view at the impact center.

TABLE 1: Tomography acquisition parameters used during imaging.

\begin{tabular}{lll}
\hline X-ray source & Detector & Tomography setup \\
\hline & & $\begin{array}{l}\text { No. of radiographs }=630 \\
\text { images }\end{array}$ \\
Power $=10 \mathrm{watt}$ & Magnification & Angle of rotation: $-110^{\circ}$ to \\
Voltage $=62 \mathrm{kV}$ & $=0.39 \mathrm{X}$ & $110^{\circ}$ \\
Current $=155 \mu \mathrm{A}$ & Filter: No & $\begin{array}{l}\text { Illumination time }=1 \mathrm{~s} \text { per } \\
\text { radiograph }\end{array}$ \\
& &
\end{tabular}

represent Figures 9(b) and 10(b) after image processing using Buehler Omnimet 9.5 software. The image processing enabled measuring the damage areas quantitatively. The green and dark red regions in Figures 9(c) and 10(c) indicate the healthy and damaged regions, respectively. Figure 9(c) suggests the presence of several delamination sites, matrix crushing, and separations (branching) of fiber bundles within inner layers. This view also shows fiber breakage of two layers close to the impact center as well as a large delamination between the third and fourth layers.

A set of virtual rulers were placed in the top and left views of both Figures 9(a) and 10(a) with the total lengths of $28,24, \ldots, 4 \mathrm{~mm}$. These rulers were used as indicators for subsequent image analyses to cut the 3D XMT images from $-14 \mathrm{~mm}$ to $+14 \mathrm{~mm}$ distance from the impact center with a spacing of $2 \mathrm{~mm}$. Images obtained from these cuts on one side of the impact center are presented in histogram forms (Figures 11 and 12). The useful length of field of view in collected tomography images was considered to be $20 \mathrm{~mm}$ 

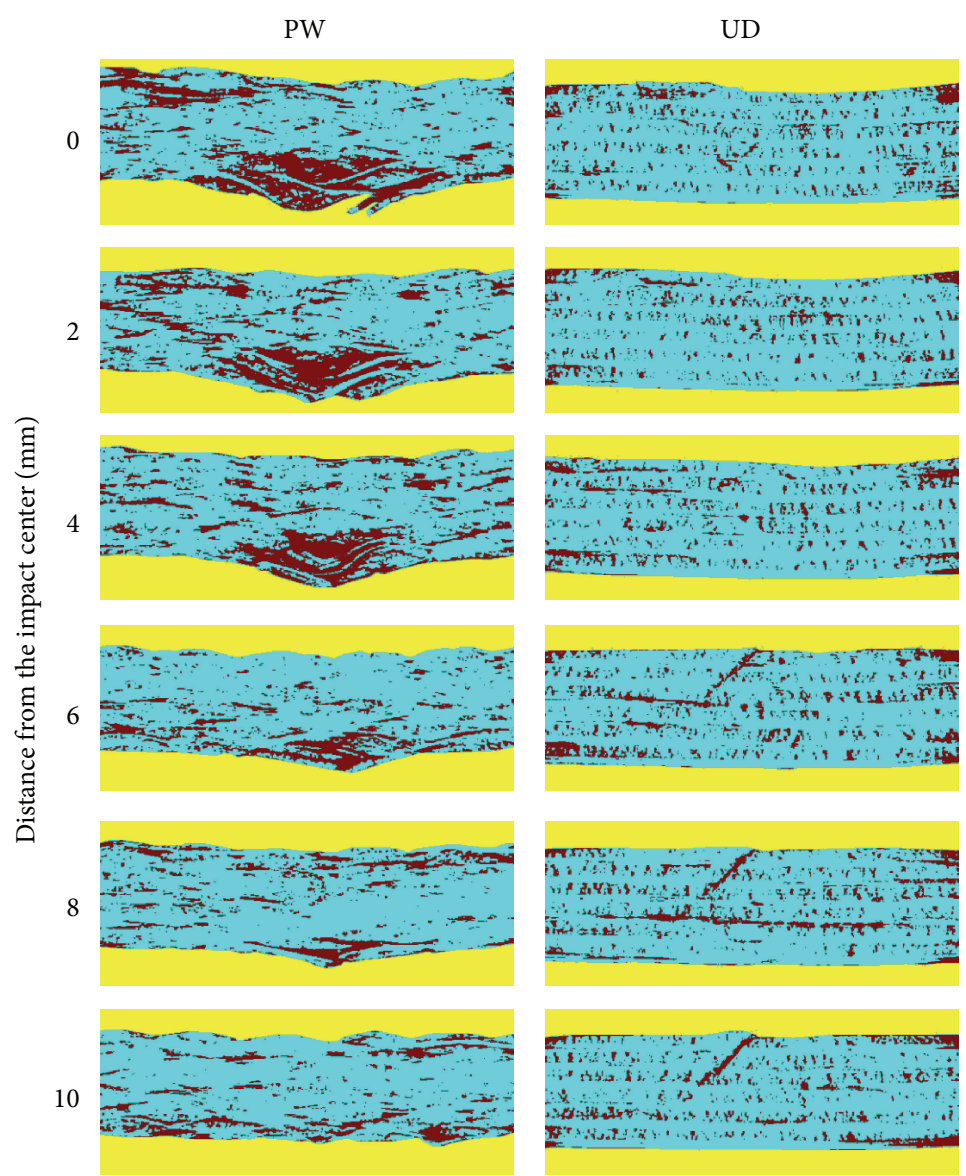

FIGURE 11: XMT top view histogram of the impacted PW and UD laminates.

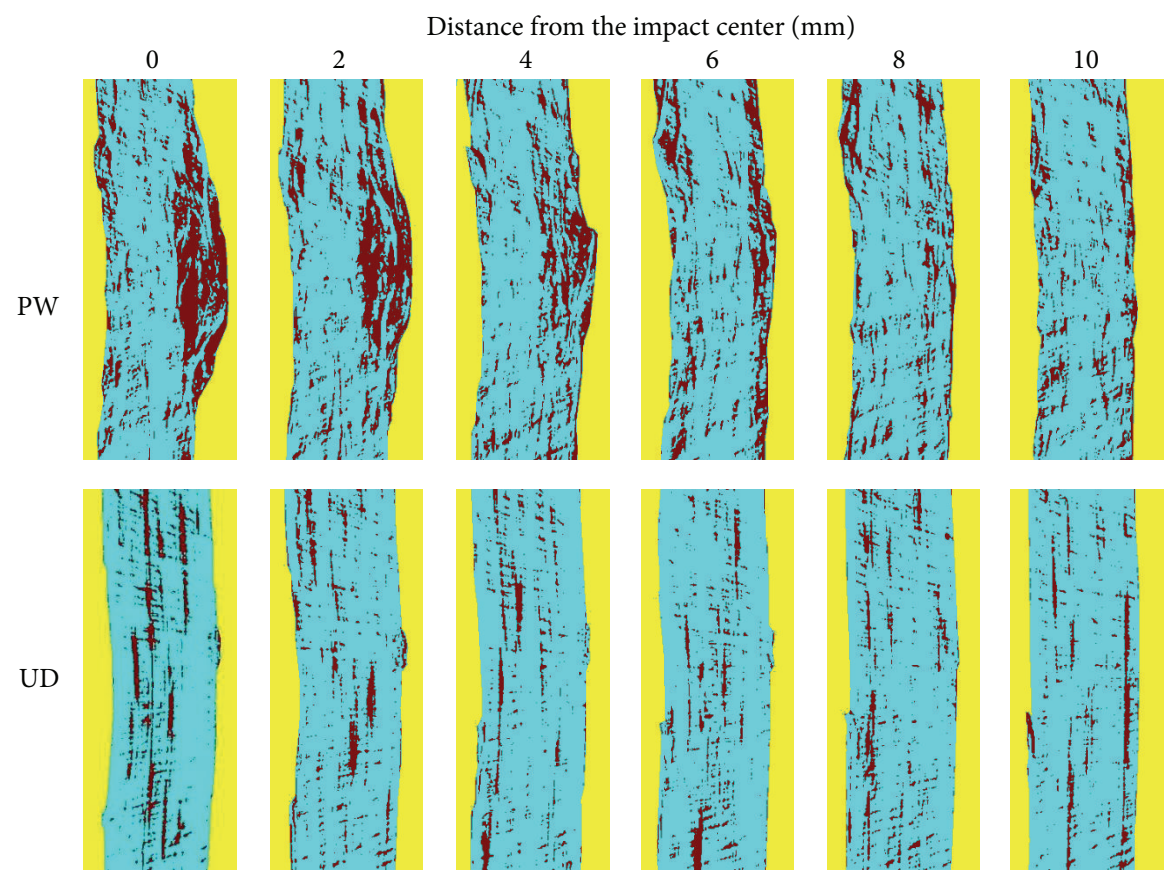

FIGURE 12: XMT left view histogram of the impacted PW and UD laminates. 


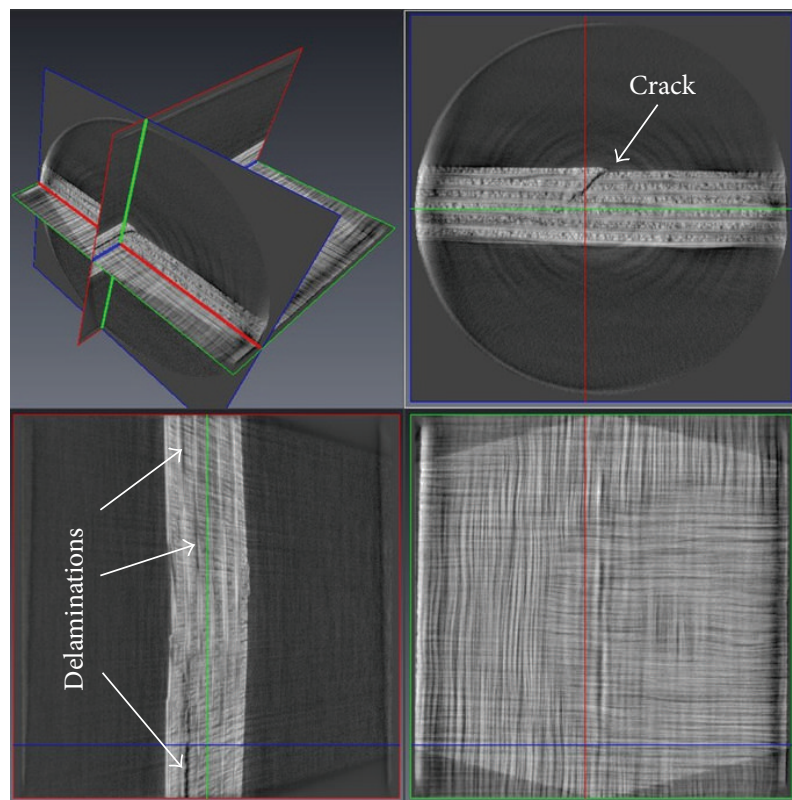

FIGURE 13: A cross-section of the impacted UD laminate showing a large through-thickness crack and clear delamination sites. A similar crack was observed in all test repeats for this material.

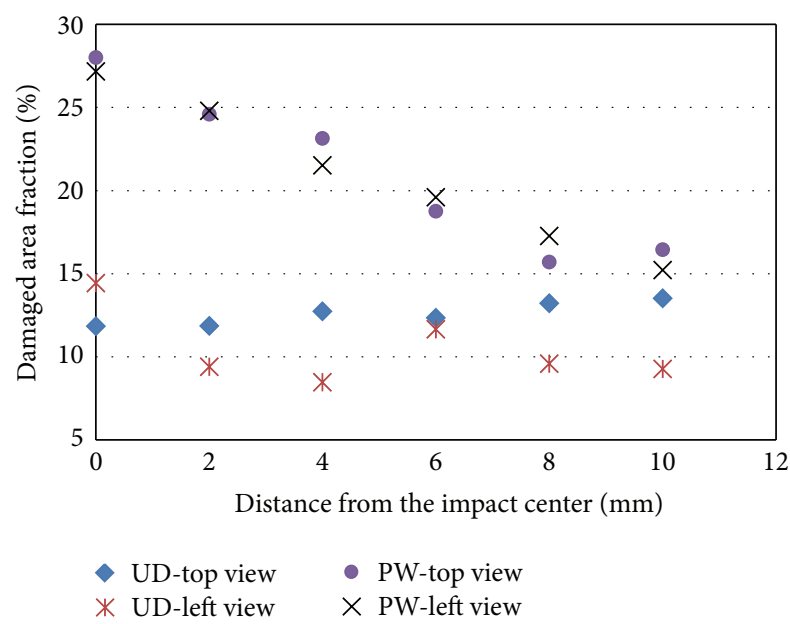

FIGURE 14: Area fraction of damaged zones in the impacted UD and PW samples, as function of distance from the impact center.

(to avoid edge effects that deteriorate the image resolution); hence the results in Figures 11 and 12 were included up to $10 \mathrm{~mm}$ (on one side) from the impact center.

Comparing results in Figures 11 and 12, it is first noticed that the states of damage at the top and left cross-sections are not generally identical, given the same cut distance from the impact center (specially for the UD sample). This is most likely because of the nonsymmetric impact boundary condition during the drop-weight tests due to the nonsquare shape of the fixture $(130 \times 80 \mathrm{~mm})$. Expectedly, cracks and delaminations have been propagated longer in the direction with larger specimen dimension, which lays on the left view of tomography images. As the cutting plane goes farther from the impact center, we notice that the PW sample appears to be more and more undamaged (comparable to the healthy state).

For UD laminates, from Figure 10(a), no severe local damage is observed under the impact center. There were, however, well-distributed small dark regions (dots) on the top view (see Figure 11 for results). Each of these dark regions would correspond to a delamination which can be traced in the corresponding left view in Figure 12. It was interesting that, in contrast to the $\mathrm{PW}$ laminate, if we go far from the impact center (up to $10 \mathrm{~mm}$ which was the maximum useful field of view), there still exits evidence of some locally delaminated zones in the UD laminate and their intensity does not decrease rapidly. This means that the extent of damage in the UD laminate in the form of several microdelaminations would be higher than that in the PW sample. Comparing the top view histograms of UD and PW laminates in Figure 11, another main difference between the two impacted materials is revealed: a very large through-thickness crack and fiber breakage have occurred in the UD laminate starting from the impacted face of the sample (marked with a white arrow in Figure 13). In fact, the calculated larger magnitude of absorbed energy in the UD laminate, $57.218 \mathrm{~J}$ versus $36.2 \mathrm{~J}$ for the PW sample, also shown in Figure 6(c), could be linked to this large through-thickness crack and fiber breakage in addition to the aforementioned distributed local delaminations across the sample. It should be added that a similar crack was visible in all test repeats of the UD material. Relating to the reinforcement architecture, the high waviness in the plain woven laminates would act as a barrier against impact pulse. On the other hand, flat UD fibers have allowed the impact wave to propagate from the center to the structure more easily without a large local damage under impactor.

Figure 14 shows the area fraction of damaged regions (dark zones) obtained quantitatively from processed images in Figures 11 and 12. Each data point in Figure 14 has been calculated from the average response of the two crosssections located symmetrically with respect to the impact center. According to the observed trends, the inner damaged area of PW samples decreases linearly by the distance from the impact center. Interestingly, in contrast to the PW sample, the damage faction of the UD sample has not varied notably by the distance from the impact center-it is nearly constant after $2 \mathrm{~mm}$ across the sample within the given field of view. This result, in turn, confirms that the damage distribution has been more uniform in the UD sample. Also Figure 14 suggests that the damage fraction of UD samples has been overall lower than PW samples. On the other hand, as discussed in the previous sections, the deterioration of effective mechanical properties from the healthy to impacted samples has been more severe in the UD material (also this material has absorbed more energy as shown in Figure 6(c)). This means that for impact damage analysis and its linkage to the residual mechanical properties in the samples, next to the damaged area, one should look into other associated parameters. One of these key parameters is the corresponding damage mode to each damaged area. Although there is no evidence of severe local damage under impact centre in UD samples, the very 
large through-thickness brittle crack and the associated fiber breakage mode, along with the distrusted delaminations, have played a significant role in the absorption of impact energy in this material.

\section{Conclusions}

$\mathrm{PP} /$ glass thermoplastic laminate samples were made using (i) unidirectional fibers (UD) and (ii) plain woven (PW) fabrics and subjected to $200 \mathrm{~J}$ impact energy as well as postimpact four-point bending. UD specimens absorbed (dissipated) more energy than the PW laminates. This was despite the fact the UD samples showed no or very little visible damage area in the outer faces. X-ray microtomography technique (XMT) was used to investigate the damage and its distribution inside the specimens. XMT analysis showed that the impact energy has been absorbed to create a severe local damage under the impact center of PW laminates, whereas well-distributed delamination zones were found across the unidirectional laminates even far from the impact center. The reason would be that unidirectional fibers allow the impact wave to propagate more easily through the structure, whereas the waviness of woven fabrics can act as a barrier for damage propagation. A large through-thickness crack was also seen inside the UD sample, which has broken 6 out of 12 layers of the laminate. In summary, this case study suggests that the rear side visible damage in impacted FRP laminates cannot represent the entire damage extension and the associated loss of effective mechanical properties (here identified through postimpact flexural testing). Microcracks and distributed local delamination sites "inside" the samples can significantly contribute to the dissipation of impact energy. A powerful nondestructive inspection method such as XMT can be used to visualize and quantify the damage state and its extent inside the specimens in 3D. Some clear differences were seen between damage states inside the impacted UD and PW laminates and suggested that reinforcement selection should be made with ultimate care depending on the objectives of a given impact application. A worthwhile future study may be the XMT analysis of hybrid laminates with varying thickness and reinforcement architecture subject to different levels of impact energy.

\section{Conflict of Interests}

The authors do not have any direct financial relation with the commercial identity mentioned in this article.

\section{Acknowledgments}

The authors wish to acknowledge financial support from the Natural Sciences and Engineering Research Council (NSERC) of Canada. Comments and suggestions of the anonymous reviewers are also greatly acknowledged.

\section{References}

[1] M. A. Ardakani, A. A. Khatibi, and H. Parsaiyan, "An experimental study on the impact resistance of glass-fiber-reinforced aluminum (Glare) laminates," in Proceedings of the 17th International Conference on Composite Materials, Edinburgh, UK, July 2009.

[2] M. A. Ardakani, A. A. Khatibi, and S. A. Ghazavi, "A study on the manufacturing of glass-fiber-reinforced aluminum laminates and the effect of interfacial adhesive bonding on the impact behavior," in Proceedings of the 11th International Congress and Exhibition on Experimental and Applied Mechanics, pp. 1948-1956, Florida, Fla, USA, June 2008.

[3] T.-W. Shyr and Y.-H. Pan, "Impact resistance and damage characteristics of composite laminates," Composite Structures, vol. 62, no. 2, pp. 193-203, 2003.

[4] J. E. L. da Silva Junior, S. Paciornik, and J. R. M. d'Almeida, "Evaluation of the effect of the ballistic damaged area on the residual impact strength and tensile stiffness of glass-fabric composite materials," Composite Structures, vol. 64, no. 1, pp. 123-127, 2004.

[5] L. M. Nunes, S. Paciornik, and J. R. M. d'Almeida, "Evaluation of the damaged area of glass-fiber-reinforced epoxy-matrix composite materials submitted to ballistic impacts," Composites Science and Technology, vol. 64, no. 7-8, pp. 945-954, 2004.

[6] C. Meola and G. M. Carlomagno, "Impact damage in GFRP: new insights with infrared thermography," Composites A, vol. 41, no. 12, pp. 1839-1847, 2010.

[7] I. M. de Rosa, C. Santulli, F. Sarasini, and M. Valente, "Postimpact damage characterization of hybrid configurations of jute/glass polyester laminates using acoustic emission and IR thermography," Composites Science and Technology, vol. 69, no. 7-8, pp. 1142-1150, 2009.

[8] L. Krstulovic-Opara, B. Klarin, P. Neves, and Z. Domazet, "Thermal imaging and thermoelastic stress analysis of impact damage of composite materials," Engineering Failure Analysis, vol. 18, no. 2, pp. 713-719, 2011.

[9] S. Wang, D. D. L. Chung, and J. H. Chung, "Impact damage of carbon fiber polymer-matrix composites, studied by electrical resistance measurement," Composites A, vol. 36, pp. 1707-1715, 2005.

[10] M. V. Hosur, C. R. L. Murthy, T. S. Ramamurthy, and A. Shet, "Estimation of impact-induced damage in CFRP laminates through ultrasonic imaging," NDT and E International, vol. 31, no. 5, pp. 359-374, 1998.

[11] F. Aymerich and S. Meili, "Ultrasonic evaluation of matrix damage in impacted composite laminates," Composites B, vol. 31, no. 1, pp. 1-6, 2000.

[12] Y. Xiong, C. Poon, P. V. Straznicky, and H. Vietinghoff, "A prediction method for the compressive strength of impact damaged composite laminates," Composite Structures, vol. 30, no. 4, pp. 357-367, 1995.

[13] A. N. Palazotto, L. N. B. Gummadi, U. K. Vaidya, and E. J. Herup, "Low velocity impact damage characteristics of Z-fiber reinforced sandwich panels-an experimental study," Composite Structures, vol. 43, no. 4, pp. 275-288, 1998.

[14] W. A. de Morais, S. N. Monteiro, and J. R. M. d'Almeida, "Evaluation of repeated low energy impact damage in carbonepoxy composite materials," Composite Structures, vol. 67, no. 3, pp. 307-315, 2005. 
[15] R. K. Luo, E. R. Green, and C. J. Morrison, "An approach to evaluate the impact damage initiation and propagation in composite plates," Composites B, vol. 32, no. 6, pp. 513-520, 2001.

[16] R. K. Luo, "The evaluation of impact damage in a composite plate with a hole," Composites Science and Technology, vol. 60, no. 1, pp. 49-58, 2000.

[17] A. MacDowell, X-Ray Micro Tomography, Advanced Light Source, Lawrence Berkley National Laboratory, 2007.

[18] G. R. Davis and F. S. L. Wong, "X-ray microtomography of bones and teeth," Physiological Measurement, vol. 17, no. 3, pp. 121-146, 1996.

[19] H. Proudhon, "Using X-ray microtomography to probe microstructure and damage of structural materials," in Proceedings of the WEMESURF Contact Course, Paris, France, June 2008.

[20] ASTM D7136, "Standard test method for measuring the damage resistance of a fiber-reinforced-polymer matrix composites to a drop-weight impact event," in ASTM Book of Standards, vol. $15.03,2005$

[21] Y. Zhang, A. Johnston, S. Ouellet, K. Williams, D. Boucher, and S. Labonte, "Low-speed impact test for foam supported composite laminates," in Proceedings of the 8th Canada-Japan joint Workshop on Composite Materials, Institute for Aerospace Research, National Research Council Canada, Boucherville, Canada, July 2010. 

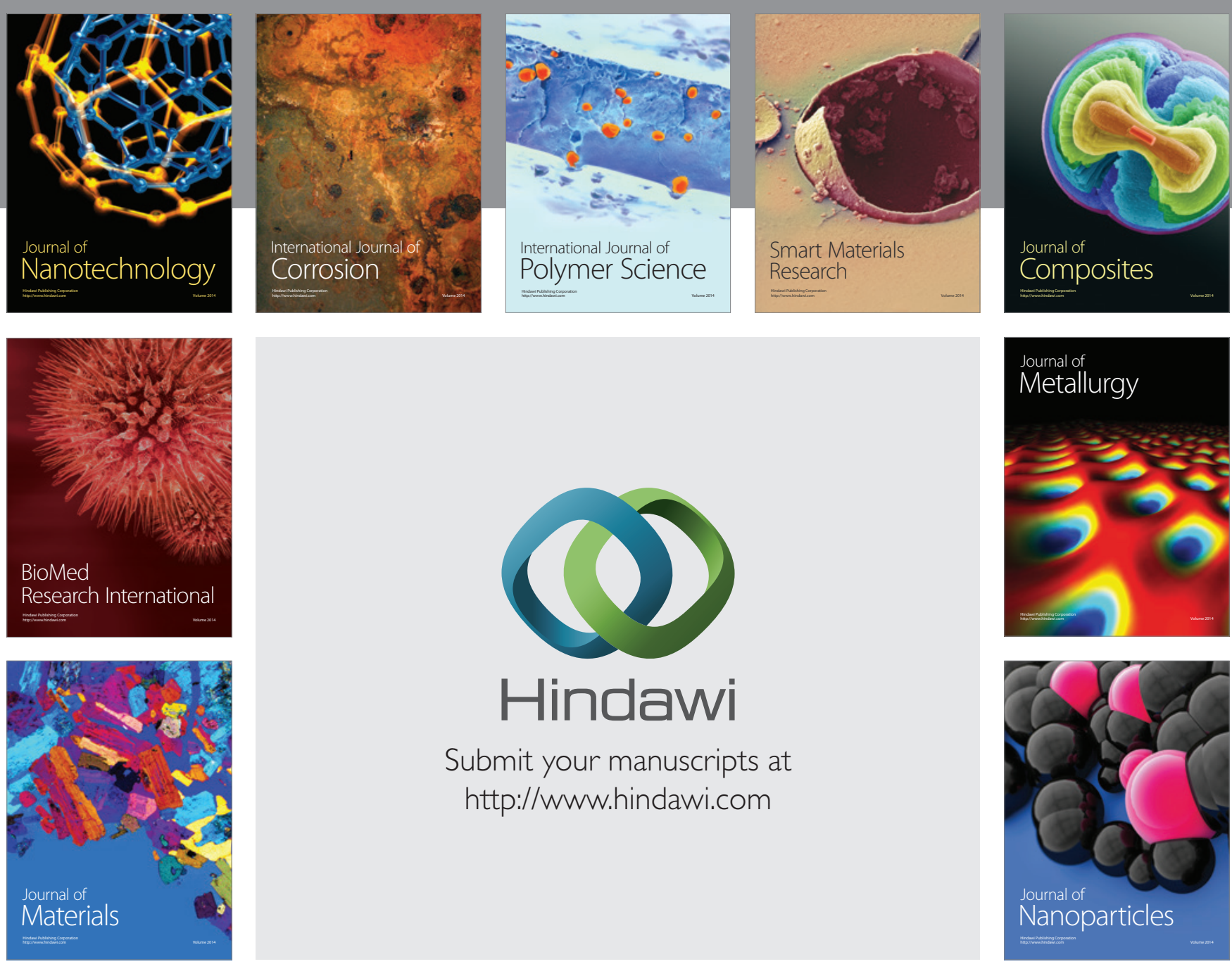

Submit your manuscripts at http://www.hindawi.com
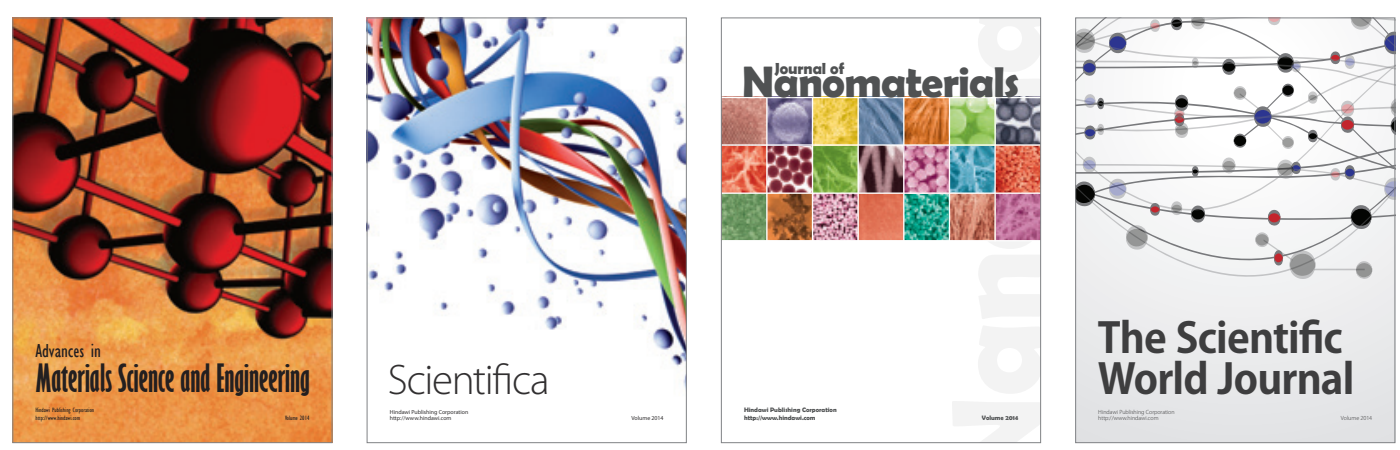

\section{The Scientific World Journal}
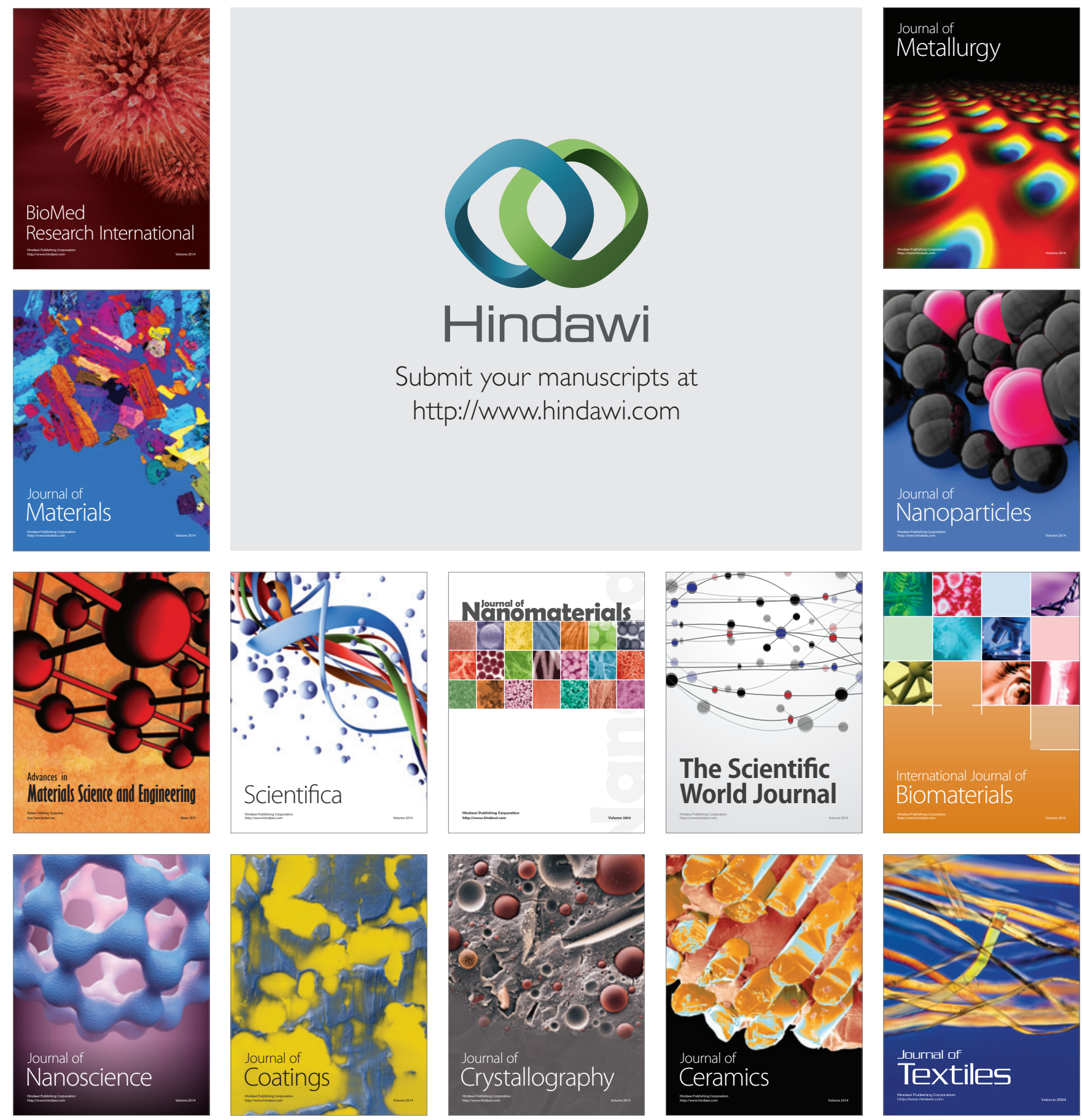